should be given to doctors entering psychiatry, and the Collegiate Trainees Committee may look at this proposal further. Junior doctors attempting to set up local representation in peripheral hospitals may be helped by invitation to the Junior staff meetings at nearby teaching centres who already have a functioning system, and this should be encouraged.

LAN MCKEITH

KEITH ROBERTS

STEPHEN Frost

CTC Representatives of N.E. Division

\section{Trainers and Trainees in Psychiatry}

A conference of trainers and trainees in psychotherapy was held on 4 November 1982 at the Royal College of Psychiatrists. The conference was organized by the JCHPT Psychotherapy Specialist Advisory Committee, and was therefore aimed primarily at bringing together those involved on both sides of the training of senior registrars in psychotherapy. The theme of the conference, 'Comparisons in Standards of Training: Recommended versus Received', provided an opportunity to discuss the difficulties faced by both trainers and trainees in following the recommendations laid down by the JCHPT.

The morning session was chaired by Dr Jonathan Pedder (Maudsley Hospital). The first speaker, Dr Jim Templeton (Chairman, JCHPT Psychotherapy Specialist Advisory Committee), outlined the recommendations of the Joint Committee. He stressed that these were not rigid requirements, since the Committee, in assessing training programmes, took into consideration the different settings in which the training took place and the individual interests of the trainers. There was, he said, no one theoretical model of training and only one firm contract between the trainer and trainee - the construction of a setting for optimal development and learning.

The conference next heard from a trainer and trainee working in London. These presentations reflected what seems to be an increasing readiness among psychotherapists in the NHS to acknowledge and discuss openly their differing theoretical and clinical orientations. Among the many positive effects of this change might be a reduction in the level of confusion among the trainees faced with the task of developing a professional identity for themselves in such a diverse specialty.

Dr John Steiner (Tavistock Clinic) gave an outline of the training required to equip one as a psychoanalytic psychotherapist. He felt that ideally this should comprise training in psychoanalysis which could then be applied to work in an NHS setting. He also mentioned the Association for Psychoanalytic Psychotherapy in the NHS, a recently formed organization among whose aims it is to advise trainees on how a training of this sort might be obtained.
Dr Felicity de Zulueta (Maudsley Hospital) entertained the audience with a highly personal account of her professional background, development and current interests (Bulletin, June $1983,7,106-7)$.

The afternoon session, chaired by Dr Michael Crowe (Institute of Psychiatry), was devoted to difficulties faced in the regions and to problems of research for the trainee. Dr Charles Lund (Newcastle) described the training programme in Newcastle as having more of the characteristics of a Range Rover than a Rolls Royce. The trainee spends two full days a week in Edinburgh at the Scottish Institute of Human Relations, and the remainder of his time is filled with an extremely impressive use of the relatively scant training resources, such that the fairly exacting recommendations of the JCHPT are met. A regional trainee, Dr Jim Atkinson (Cambridge), told of his personal experience of the sort of problem which can be encountered in the regions.

Moving on to problems of research, Dr Sidney Bloch (Oxford) said that trainees in psychotherapy tend to assign a relatively low priority to this, the main reason being the traditional gulf between the clinicians and researchers in psychotherapy and the confusion over different theoretical approaches. There is a possibility that psychotherapy attracts trainees of an 'arty' rather than a 'scientific' temperament. The solution to this problem lay in nurturing in the trainee a respect for a scientific approach to his work. Dr Averil Stedeford (Oxford) talked of her own research which had grown out of 'an attitude of enquiry' in her clinical work. She considered this attitude to be essential in an aspiring researcher.

In the final plenary session there was general agreement that the conference had been enjoyable and valuable.

DEnIS V. CARPY Tavistock Clinic

\section{Forum on Formulation}

The first Trainces' Forum organized by the Collegiate Trainees Committee (CTC) was held at the College's Spring Quarterly Meeting in London in February 1983. The Committee was delighted by the high attendance.

The forum was chaired by Dr P. F. Thomas (ViceChairperson, CTC) whose opening remarks introduced the topic for discussion-formulation. The first speaker, Dr J. A. Hollyman (Chairperson, CTC), presented the results of two surveys on the concept of formulation undertaken in conjunction with Dr L. Hemsi (Bulletin, August 1983, 7, 140-43). Dr Maurice Greenberg discussed the 'Guidelines to Formulation' published in the Bulletin last year (September 1982, 6, 160-2) with Drs Szmukler and Tantam. It was not intended that the framework they had suggested should be slavishly adhered to, but they enabled the trainee to select and organize material more efficiently. This ability, which should result in a coherent account of a patient, was one of the clinical skills examined. Dr Greenberg called upon the 